\title{
COMPUTATIONLESS PALM-PRINT VERIFICATION USING WAVELET ORIENTED ZERO-CROSSING
}

\author{
Jitendra Prabhakar Chaudhari ${ }^{1}{ }^{*}$, Hiren Kantilal MeWAdA ${ }^{2}$ \\ Amit Vinubhai Patel ${ }^{1}$, KeyUr Kamaldasji Mahant ${ }^{1}$, \\ AlPesh DUdabhai Vala ${ }^{1}$ \\ ${ }^{I}$ CHARUSAT Space Research and Technology Centre, \\ Department of Electronics and Communication Engineering, CSPIT, \\ Charotar University of Science and Technology, Changa, Gujarat, India \\ ${ }^{2}$ Department of Electrical Engineering, Prince Mohammad Bin Fahd University, \\ Kingdom of Saudi Arabia \\ ${ }^{*}$ Corresponding author: jitendrachaudhari.ec@charusat.ac.in
}

(Received: 27th May 2021; Accepted: 15 th July 2021; Published on-line: $4^{\text {th }}$ January 2022)

\begin{abstract}
Palmprints can be characterized by their texture and the patterns of that texture dominate in a vertical direction. Therefore, the energy of the coefficients in the transform domain is more concentrated in the vertical sideband. Using this idea, this paper proposes the characterization of the texture features of the palmprint using zerocrossing signatures based on the dyadic discrete wavelet transform (DWT) to effectively identify an individual. A zero-crossing signature of $4 \times 256$ was generated from the lower four resolution levels of dyadic DWT in the enrolment process and stored in the database to identify the person in recognition mode. Euclidean distance was determined to find the best fit for query palmprints zero-crossing signature from the dataset. The proposed algorithm was tested on the PolyU dataset containing 6000 multi-spectral images. The proposed algorithm achieved $96.27 \%$ accuracy with a lower recognition time of 0.76 seconds.
\end{abstract}

ABSTRAK: Pengesan Tapak Tangan boleh dikategorikan berdasarkan ciri-ciri tekstur dan corak pada tekstur yang didominasi pada garis tegak. Oleh itu, pekali tenaga di kawasan transformasi adalah lebih penuh pada jalur-sisi menegak. Berdasarkan idea ini, cadangan kajian ini adalah berdasarkan ciri-ciri tekstur pada tapak tangan dan tanda pengenalan sifar-silang melalui transformasi gelombang kecil diadik yang diskret (DWT) bagi mengecam individu. Pada mod pengecaman, tanda pengenalan sifar-silang 4 x 256 yang terhasil daripada tahap diadik resolusi empat terendah DWT digunakan dalam proses kemasukan dan simpanan di pangkalan data bagi mengenal pasti individu. Jarak Euklidan yang terhasil turut digunakan bagi memperoleh padanan tapak tangan paling sesuai melalui tanda pengenalan sifar-silang dari set data. Algoritma yang dicadangkan ini diuji pada set data PolyU yang mengandungi 6000 imej pelbagaispektrum. Algoritma yang dicadangkan ini berjaya mencapai ketepatan sebanyak $96.27 \%$ dengan durasi pengecaman berkurang sebanyak 0.76 saat.

KEYWORDS: $m u l t i-s c a l e ~ e d g e$ detection; palmprint recognition; feature extraction

\section{INTRODUCTION}

People authentication is now a necessity in the digital world. Biometric-based identification is considered to be a most reliable system for protection and reliable authentication. In the current mechanization era, artificial intelligence systems prepare 
data about everything and use it to solve several complex problems. Although many organizations have built state of the art security systems, recent terrorist attacks have uncovered significant vulnerabilities in complex security schemes. Consequently, various organizations look to the uniqueness of each human body to establish information frameworks, often called biometrics, because they are more "real" or more difficult to counterfeit. Automatic personal identity recognition can be accomplished through the use of different biometric identifiers. In many biometric baseline systems, anatomical individuality such as thumbprints, fingerprints, and morphology of the iris, retina, head, nose, or hand or behavioral characteristics such as signature, keystroke mechanics, and gait are used for identification. Each biometric innovation has its own particular merits and constraints, and therefore no system exists with better performance for all applications [1].Biometric System, which uses the iris, is one of the mainstream biometric frameworks with exceptionally high precision [2]. Since the iris acquisition method is costly, it requires very high cooperation from the user and has a high failure rate of enrolment. Because of their simplicity, good accuracy, and low cost, face and finger print recognition have gained a large popularity. However, the present COVID situation makes these systems fail from occlusion due to masks hiding the facial features and frequent sanitization reducing the fingerprint features [3]. Recently, a hand geometry-based identification has been proposed in [4]. However, this system is tedious, sensitive to the acquisition process, and computationally complex. New emerging ear trait recognition is explained in [5]. Mewada et al. [5] used CNN for learning and discriminating between ear features. A moving human leg angle-based gait recognition system, explained in [6], uses average statistical features of eight frames.

A palmprint-based identification system has many advantages compared to other biometric systems: 1) Hand features of the human have high stability and uniqueness. 2) For data, acquisition needs extremely minimal support from clients. 3) Non-intrusive data collection. 4) Inexpensive devices are sufficient to acquire good data quality. 5) The mechanism provides high accuracy and uses low-resolution images. 6) More features can be extracted from palmprints as it allows for a larger surface area compared to fingerprints. 7) Since low-resolution imaging sensors are used for acquiring palmprint images, the computation required for pre-processing and extracting features is minimal. 8) palmprints can be considered a trustworthy human identifier as these patterns are unique in monozygotic twins [7].

Therefore, this paper presents a unique approach requiring less computation and complexity in the palmprint recognition process. The proposed system is sustainable with low memory devices and makes it suitable for embedded platform implementation.

\section{LITERATURE STUDY}

A recent advancement in machine learning has obtained the greatest attention in classification models. Various deep learning based neural networks outperformed the traditional methods of classification, achieving enormous classification accuracy. Jia et al. [8] presented a detailed study on various deep learning-based palmprint recognition algorithms. All these algorithms succeeded in achieving classification accuracy ranging from $80 \%$ to $100 \%$. From the computation study, it has been observed that GPU based computation efficient architecture requires at least 390M FLOP operations (i.e. ScarletNAS architecture) and minimum identification time of $183 \mathrm{~ms}$ for NASNet architecture (excluding training time). Thus, deep learning provides the highest accuracy at the cost of computation time and hardware complexity. 
Another comparative analysis of palmprint recognition was presented in [9]. This study involved all traditional methods used in multispectral recognition including principle component analysis, Fisher linear discrimination, fuzzy method, edge map generation, radon transform, etc. Bounneche et al. [10] used oriented log-Gabor filters to enhance the recognition rate. Features obtained from the log-Gabor filters were matched using hamming distance for palm identification. The feature extraction required an average time of $894 \mathrm{~ms}$ and a matching time of around $5.6 \mathrm{~ms}$.

To tackle the problem of misalignment, a Local Micro-structure Tetra Pattern (LMTrP) based local feature extraction was proposed in [11]. Initially, Gabor based features were obtained and later a histogram using LMTrP in local regions was generated for matching purposes. Raghavendra et al. [12] proposed discrete wavelet transform based multi-spectral fusion of palm features. They extracted the average coefficients from DWT from each spectrum of the palm and fused these coefficients based on a weighted function. Then inverse DWT was calculated to get a fusion of ROI from the wavelet domain. For identification purposes, Gabor filters were used with distance calculation. They achieved a 5.97 error rate in classification. The overall method was complex, as it requires multiple spectrum's DWT feature fusion.

The moving human leg angle-based gait recognition system is explained in [13] and uses average statistical features of eight frames. A least square regression model named salient and discriminative descriptor learning method described in [14] solved the sparse nonnegative noise interference error problem. Kokila et al. used PCA to extract the features and an ANN model for matching purposes [15]. A simple basic operation (additions and subtractions) based method that forms code for a palmprint is described in [16]. Chaudhari et al. [17] used a Histogram of Radon transform for feature extraction from low resolution images.

Jaafar et al. [18] touched on a less recognized algorithm, where a mobile camera was used for palm acquisition. They used histogram equalization and thresholding for feature extraction. A Fuzzy based nearest centroid neighbor was proposed for palm recognition achieving accuracy of $98.78 \%$. Hong et al. [19] de-blurred palm images using a Gaussian Focused degradation model and a Vese-Osher decomposition model was used to extract the texture features from ROI. The normalized correlation coefficient was calculated to find the similarity between two palms and obtained 0.9210 EER.

A sparse based image enhancement, PCA based dimensionality reduction and voting based recognition, was proposed in [20]. This algorithm was tested on a PolyU dataset and obtained a 99.87\% accuracy. Tamrakar and Khanna [28] used approximation coefficients obtained from the Haar wavelet for feature extraction. Further, the image was processed with a Gaussian derivative to obtain local phase information. Later,a block-based histogram was used as a feature vector for recognition. They claimed $100 \%$ recognition rate on PolyU dataset. Their extraction time and recognition time were lower (i.e. 16.942 $\mathrm{ms}$ and $188.4471 \mathrm{~ms}$ ) but the training time requirement was $3502 \mathrm{~ms}$.

This paper presents a unique approach where feature extraction and matching require less time and make the system approachable to real-time. The proposed system uses dyadic wavelet transform, which is fast and compatible with hardware as it works in discrete and power of 2 . The discriminative features obtained using signature formation makes it robust for intra-variation. Further, reduction in matching time is obtained with exclusion of the coarsest level features. 


\section{DISCRETE DYADIC WAVELET TRANSFORM}

Edges of the palm print are important features in the recognition process. An edge can be thought of as a series of fast transitions in image amplitude. For a given image $\mathrm{f}(\mathrm{x}, \mathrm{y})$, the image gradient $|\nabla \mathrm{f}(\mathrm{x}, \mathrm{y})|$ takes a local maximum value indicating the edge. However, image texture also obtains a similar transition. Therefore, to discriminate the edge from the texture, scale factor needs to be considered in the calculation. The dyadic wavelets that account for the scaling and smoothing function can easily discriminate the edges from the texture regions. The DDWT of image $f(x, y)$ calculated multi-scale edge at point $(\mathrm{s}, \mathrm{t})$ can be expressed as

$$
W_{j}^{k}(s, t)=<f(x, y) \varphi_{j}^{k}(x-s, y-t)>
$$

where $\mathrm{j}$ and $\mathrm{k}=1,2$ are integers and $\varphi$ is the wavelet function which can be expressed as

$$
\varphi_{j}^{k}(x, y)=2^{\frac{j}{2}} \varphi\left(2^{j}(x, y)-k\right)
$$

The modulus of DDWT $\left|W_{j}^{k}(s, t)\right|$ reaches a maximum value locally in the neighbourhood of point $(s, t)$. Similar to the 1D example, the scale dependency of the magnitude of the modulus maxima is applied to the Hölder exponent of $f(x, y)$ and hence provides knowledge to differentiate between edges and textures.

For a certain decision of wavelets, the DDWT change can be executed inside a fast hierarchical digital filtering scheme using multi-resolution analysis. A Mallat pyramid based hierarchical filtering to obtain DDWT is shown in Fig.1.

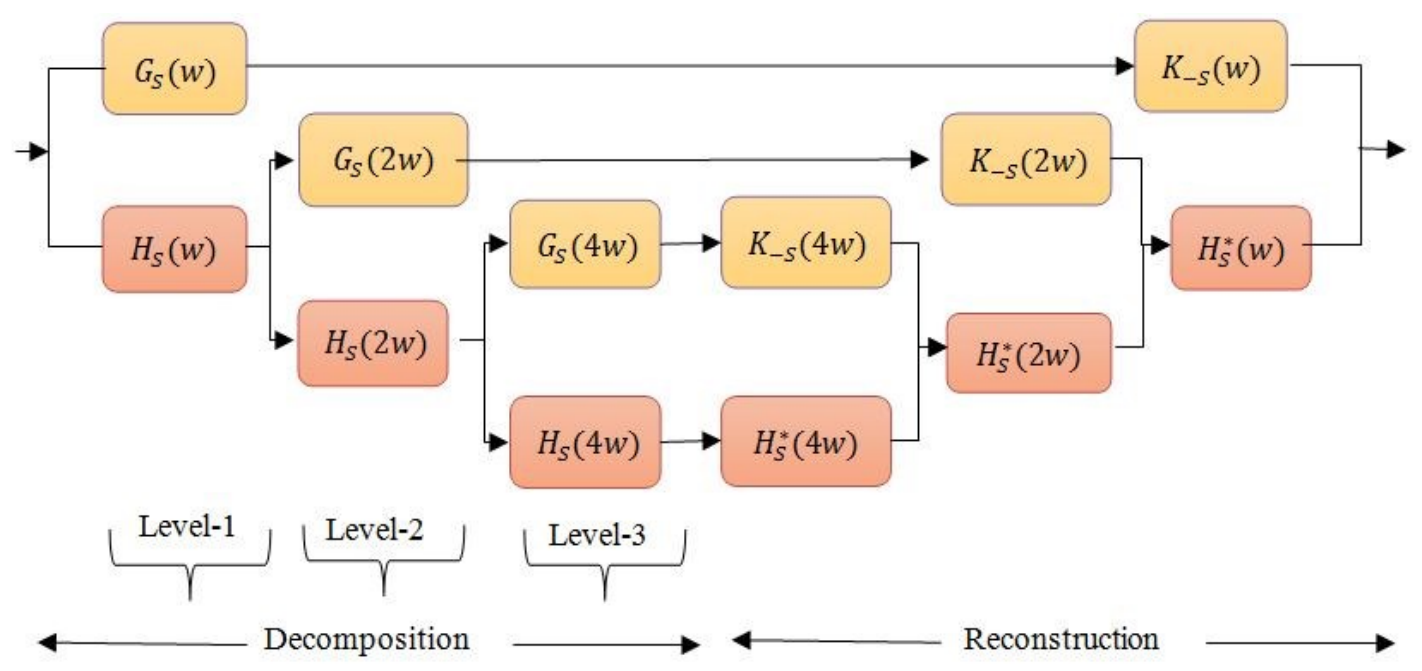

Fig.1: Filter bank realization of a 1-D dyadic DWT at three levels (left) of DWT decomposition and (right) DWT reconstruction, where $\mathrm{G}(\mathrm{w})$ is a complex conjugate of $\mathrm{H}(\mathrm{w})$.

In Fig.2, $H(\omega)$ is a low pass filter, $G(\omega)$ is a high pass filter, and $K(\omega)$ is a high pass filter for $r=1$ and a low pass filter when $r=2$ and $p>0$. Figure 2 represents the successive partition of the frequency spectrum. The initial frequency spectrum of $[0, \pi]$ is divided into equivalent subintervals i.e. $[0, \pi / 2]$ and $[\pi / 2, \pi]$. The upper spectrum has $T / 2$ DDWT coefficients. These coefficients are the basis for the next level. In the next level of the decomposition from the previous level-1, the lower spectrum is further subdivided into two equal subintervals i.e. $[0, \pi / 4]$ and $[\pi / 4, \pi / 2]$.The subdivision process proceeds, successively separating the lower subintervals until it can no longer go any further. 
Let the sampling shifted digital filter be expressed $\operatorname{as}_{s}(\omega)=e^{-j \omega s} F(\omega)$. This digital filter can be formulated to divide the spectrum into two intervals. The required condition in the design of these filters is that filters should be asymmetrical and they should have small compact support. The family $G(\omega), H(\omega)$ and $K(\omega)$ that satisfy these conditions is expressed as

$$
H(\omega)=e^{j \omega / 2}\left(\cos \left(\frac{\omega}{2}\right)\right)^{2 p+1} G(\omega)=4 J e^{j \omega / 2}\left(\sin \left(\frac{\omega}{2}\right)\right)^{r} K(w)=\frac{1-|H(w)|^{2}}{G(w)}
$$

In the opposite operation of the decomposition referred as reconstruction, the signals are up-sampled to obtain the signal back. A unique approach of signature formation from these wavelet decompositions and reconstructions has been proposed in next section.

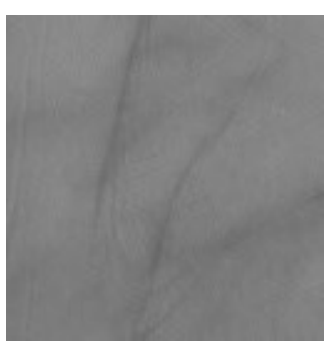

(a)

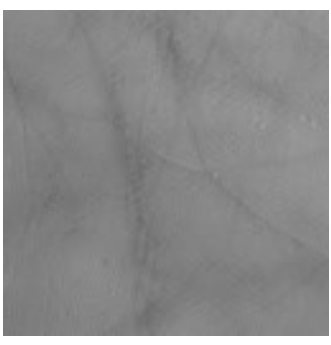

(a)

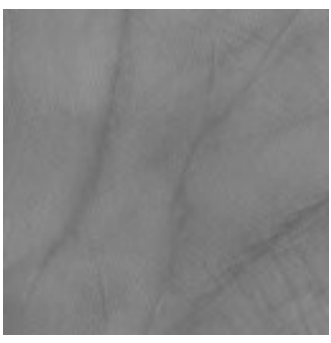

(a)

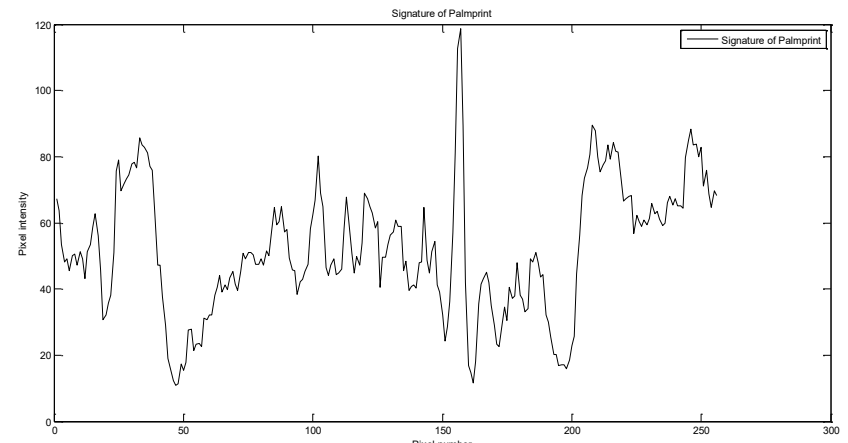

(b)

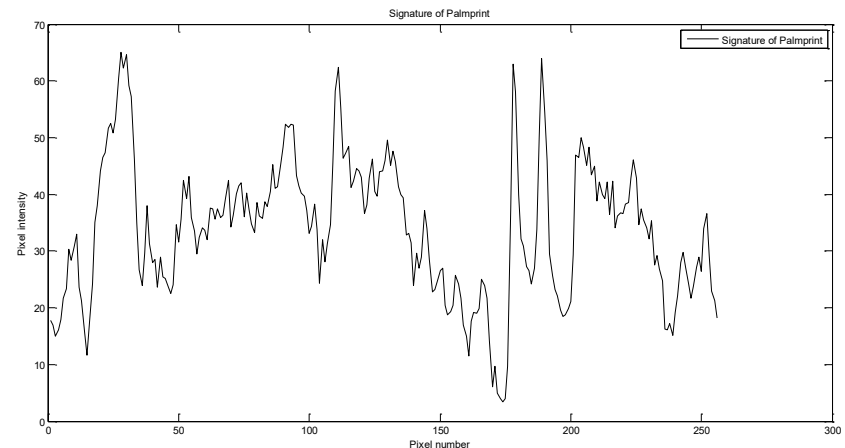

(b)

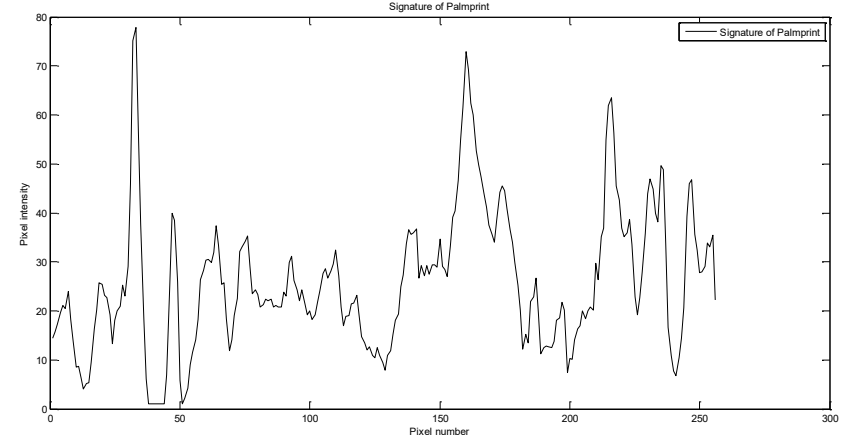

(b)

Fig.2: Sample palm print signatures (a) palmprint ROI (b) corresponding PS obtained with reference to the horizontal line passed from the center of the extracted ROI.

\section{PALMPRINT FEATURE EXTRACTION USING DDWT}

The basic requirement in palmprint recognition is that obtained features shall be translation and rotation invariant. Therefore, the region providing distinguished features 
must be obtained first to extract these features. This region extraction process, consisting of five steps, is well explained in [21]. The main contribution of this paper lies here. The traditional wavelet approach uses multi-resolution edge-oriented features i.e. principle lines of palms, ridges i.e. loop, arch and whorl or cores and delta in the recognition process. This paper proposes the formation of zero-crossing signatures using DDWT. The DDWT is applied to this region providing unique features for recognition. These steps to obtain the zero-crossing signature of each palm are as follow:

The palmprint's extracted ROI has been used to plot the signature in the preprocessing operation step. To get the signature, a horizontal line is passed through the center of the ROI. The pixel intensities are recorded on that line and a corresponding unique signature has been generated for each palmprint. Figure 2 demonstrates the unique signatures obtained from three different palmprints.

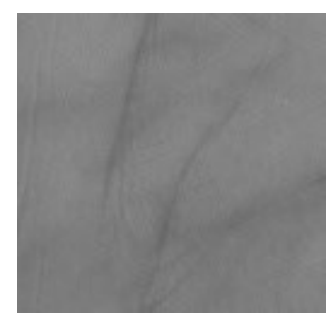

(a)

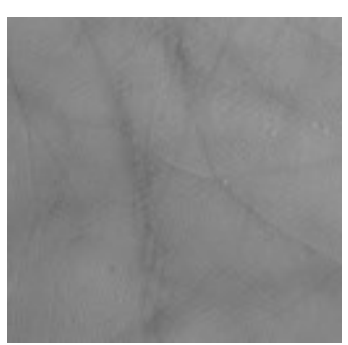

(a)

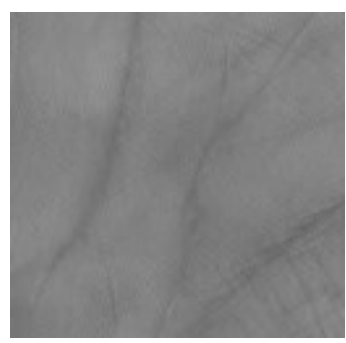

(a)

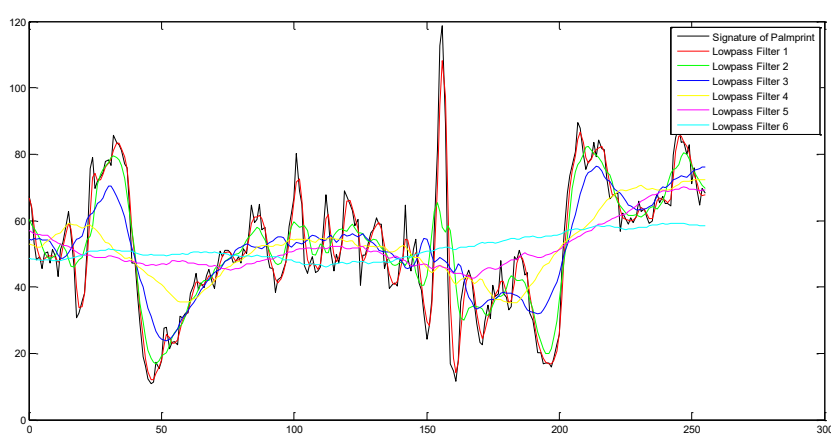

(b)

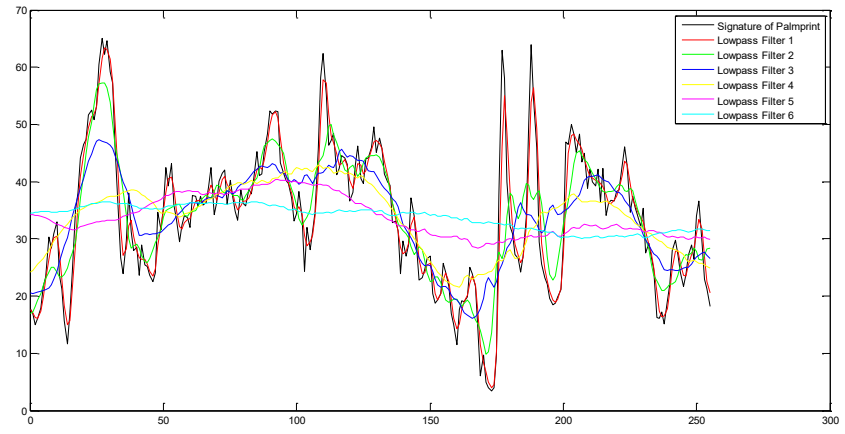

(b)

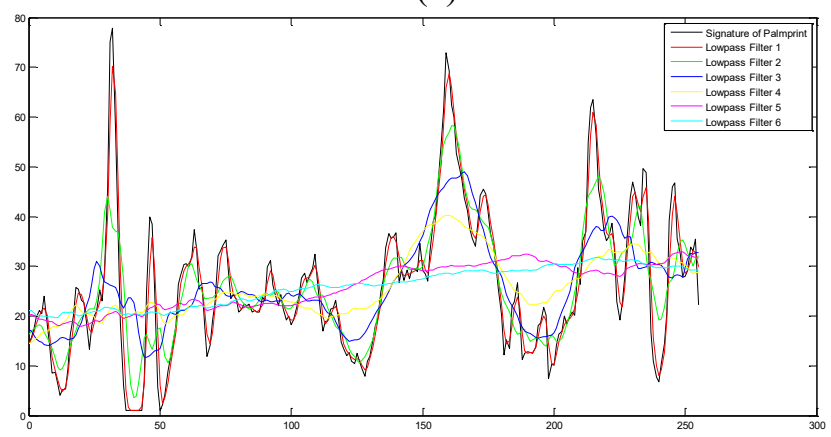

(b)

Fig.3: The palmprint signatures at various scales (a) extracted ROI of palmprint, (b) corresponding PS along with six resolution levels of the DDWT.

The signals obtained using a piecewise constant function between sequences of two consecutive zeros are used as unique features to represent the palmprint instead of the zerocrossing of the wavelet transform at various scales. This signal is referred to as a Piecewise Constant function of Palmprint Signature (PCPS). For DDWT, all scales are restricted 
with power of 2 only. The PS has been calculated with a finite resolution that forces a finer scale while calculating the dyadic wavelet transform instead of computing the wavelet transform on all scales of $2^{j}$ for $\mathrm{j}$ varying from $-\infty$ to $+\infty$. The resolution is restricted by the finite larger scale and a nonzero finer scale. For implementation purposes, the finer scale is equal to 1 and the largest scale is $2^{j}$. Further experimentation has been carried out at different resolution/scales of DDWT. Figures 3 and 4 present the PS and corresponding PCPS obtained using DDWT at various scales.

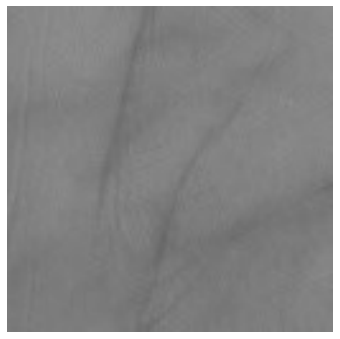

(a)

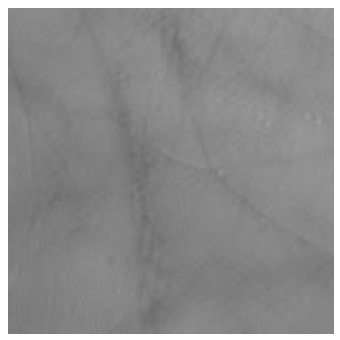

(a)

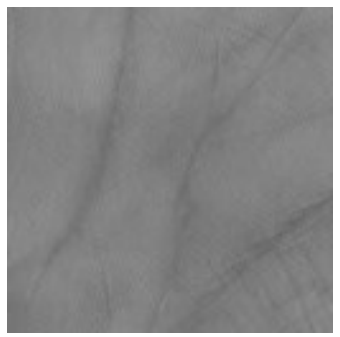

(a)

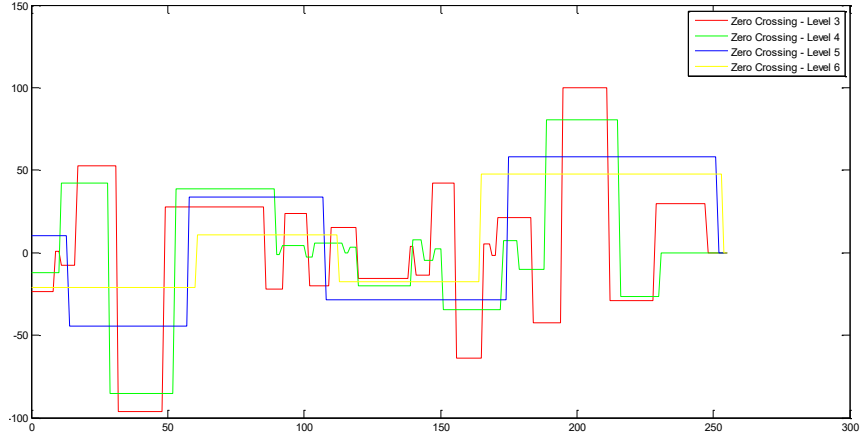

(b)

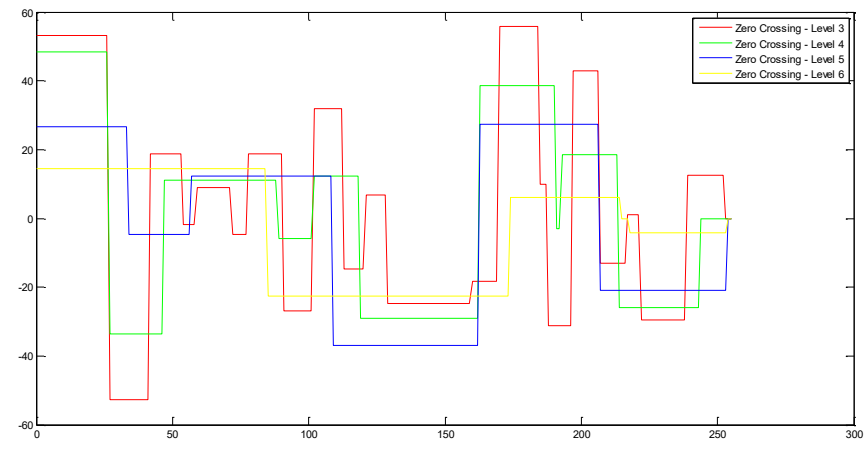

(b)

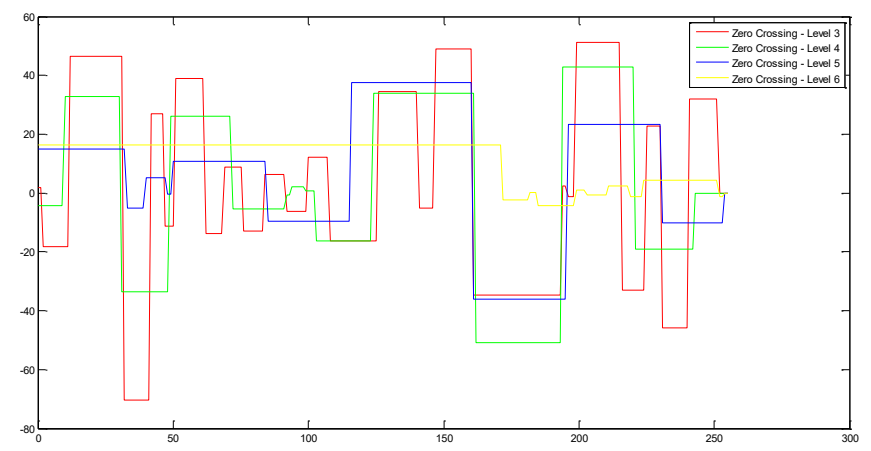

(b)

Fig.4: Piecewise constant function representation of PS (a) extracted ROI of palmprint, (b) PCPS corresponding to the lowest four resolution levels of the dyadic wavelet transform.

\section{RESULTS AND DISCUSSION}

PolyU database [23], available on the internet, has been used for dyadic DWT testing for palmprint images as unimodal biometrics. In the experiment, 4 level dyadic decomposition was used. Features based on discrete dyadic wavelets were measured to evaluate the performance accuracy of the proposed algorithm. When testing the algorithm, each image from the database was matched with the same dataset's remaining images. 
If the test image matched another image in the dataset, it was counted as correct matching. Otherwise, it will be counted as incorrect matching. In the matching method, the Euclidean distance between the feature sets was used. The minimum Euclidean distance amongst two palmprints' features was considered the best fit for the test image for stored prototypes. The system's performance was calculated using false acceptance ration (FAR) and genuine acceptance ration (GAR).

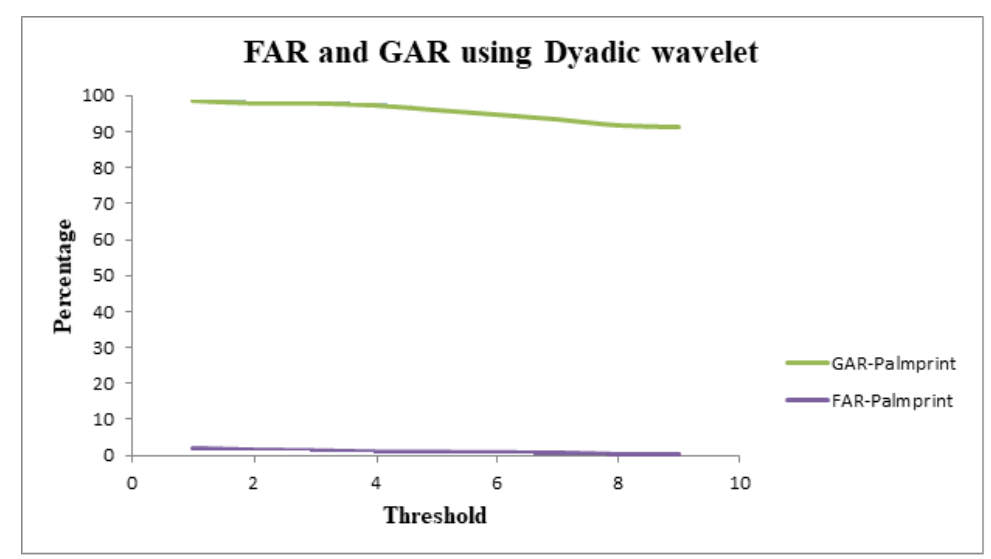

Fig.5: Performance of the proposed algorithm of person identification using discrete dyadic wavelet transform in terms of percentage FAR and GAR plotted at various thresholds.

FAR represents that the system has accepted and recognized the imposter, and its values must be as low as possible. GAR means true acceptance of the user. The FAR and GAR percentages for palmprints were plotted, taking into account various threshold values. Fig. 6 shows this performance plot. The maximum recognition accuracy of $96.27 \%$ is achieved for palmprint images from the PolyU database using dyadic DWT. The testing time of 0.76 seconds indicates the computational efficiency of the algorithm. The Table 1 discusses the comparative analysis of the proposed DWT based signature model with other DWT based palmprint recognition models.

Table 1: Palmprint recognition accuracy comparison using DWT approaches

\begin{tabular}{|c|c|c|}
\hline Authors & Key Points & Max. Accuracy \\
\hline Kozik and Choraś [24] & $\begin{array}{l}\text { Haar wavelet transform based } \\
\text { geometrical feature extraction }\end{array}$ & $94 \%$ \\
\hline Giełczyk et al. [25] & $\begin{array}{c}\text { Computationless geometric feature } \\
\text { extraction }\end{array}$ & $91 \%$ \\
\hline $\begin{array}{l}\text { L. Zhang and } \\
\text { D. Zhang [26] }\end{array}$ & $\begin{array}{c}\text { Fusion of signatures of gravity, density, } \\
\text { spatial disperse and energy in DWT } \\
\text { domain }\end{array}$ & $98 \%$ \\
\hline Agrawal et al. [27] & $\begin{array}{l}\text { Curvelet transform based energy } \\
\text { computation }\end{array}$ & $85 \%$ \\
\hline $\begin{array}{l}\text { Chaudhari et al. } \\
\text { (Proposed method) }\end{array}$ & $\begin{array}{c}\text { Zero crossing signature using Dyadic } \\
\text { DWT }\end{array}$ & $96.27 \%$ \\
\hline
\end{tabular}

Kozik and Choraś [24] developed geometric characteristics from the Haar wavelet transform and Giełczyk et al. [25] proposed a further reduction in computation. Zhang and Zhang [26] calculated the statistical signatures across all the DWT scale using the density, energy, gravity, and dispersivity and achieved an accuracy of $98 \%$ at the cost of high future sets. In contrast, the proposed method uses the zero-crossing points to establish a 
signature size of $4 \mathrm{X} 256$ and can achieve near-by precision at the lower future level. Thus, the strategy proposed is more effective than other methods focused on the DWT.

Table 2 presents the computational time requirement from the literatures section. As discussed, machine learning approaches can achieve better performance but at the cost of long computation i.e. training time. Table 2 suggests that the accuracy of the traditional methods is also better and require less execution time. Here, the extraction of the palm region has not been considered and computation has been partitioned into two parts: the feature extraction process and the matching process. Gabor-based approaches require a long time for feature extraction since the large number of orientations and scales in Gabor forms the large number of features. Therefore, their feature extraction time is large. Wavelet has only four bands per unit decomposition and therefore, it requires less execution time in comparison with Gabor. Therefore, the proposed approach requires shorter execution time of $21.04 \mathrm{~ms}$ including only feature extraction and matching.

Table 2: Computation time comparison with related techniques

\begin{tabular}{|c|c|c|c|c|}
\hline Reference & Method & $\begin{array}{c}\text { Feature } \\
\text { extraction time } \\
(\mathrm{ms})\end{array}$ & $\begin{array}{l}\text { Recognition } \\
\text { time (ms) }\end{array}$ & $\begin{array}{c}\text { Accuracy } \\
(\%)\end{array}$ \\
\hline $\begin{array}{l}\text { Bounneche et al. } \\
{[10]}\end{array}$ & $\begin{array}{l}\text { Gabor filter and } \\
\text { Hamming Distance }\end{array}$ & 894 & 5.6 & 99.33 \\
\hline Li et al. [11] & $\begin{array}{l}\text { Gabor filter + LMTrP } \\
\text { histogram + Euclidean } \\
\text { distance }\end{array}$ & 82.68 & - & 95.60 \\
\hline $\begin{array}{l}\text { Raghavendra et al. } \\
\qquad[12]\end{array}$ & $\begin{array}{l}\text { Fusion of Haar DWT } \\
\text { features from multiple } \\
\text { spectrum }\end{array}$ & - & $\begin{array}{l}42000 \\
\text { (Total) }\end{array}$ & 96.52 \\
\hline Tamrakar et al. [28] & & 16.94 & 304 & 99.98 \\
\hline Hong et al. [18] & $\begin{array}{l}\text { Debluring }+ \text { Vese- } \\
\text { Osher decomposition } \\
\text { model }\end{array}$ & 30.9 & 0.059 & 99.07 \\
\hline Jaafar et al. [19] & $\begin{array}{c}\text { Histogram equalization } \\
\text { + Thresholding }+ \\
\text { Fuzzy K nearest } \\
\text { centroid neighbor }\end{array}$ & - & $\begin{array}{c}255 \\
\text { (Total) }\end{array}$ & 98.78 \\
\hline Imad et al. [20] & $\begin{array}{c}\text { Sparse Representation }+ \\
\mathrm{PCA}+2 \mathrm{D}-\mathrm{LDA}+ \\
\text { Voting }\end{array}$ & - & 600 (total) & 99.87 \\
\hline Proposed & $\begin{array}{c}\text { DWT + Palmprint } \\
\text { Signature }\end{array}$ & 20.25 & 0.76 & 96.27 \\
\hline
\end{tabular}

\section{CONCLUSION AND FUTURE SCOPE}

The fusion of features, i.e. multi-modal biometric, improves the accuracy at the cost of complexity and execution time. This paper presented an alternative to these two problems. Dyadic DWT has been used in palmprint retrieval and identification. The energy of dyadic DWT is more concentrated in the vertical sideband. Therefore, a DWT based multi-resolution analysis is performed to obtained coefficients characterizing the palm. A zero-crossing signature is created to represent the texture features of the palm ROI using this sideband. The goal is to cut out recognition time and ensure recognition accuracy. The recognition accuracy has been improved to $96.27 \%$ without the fusion of 
multiple features. Therefore, we can say that it provides a light-weight palmprint verification framework. This may be aimed for mobile applications in the future.

\section{REFERENCES}

[1] Zhang DD. (2004) Palmprint authentication. Springer Science \& Business Media.

[2] Kim D, Jung Y, Toh KA, Son B, Kim J. (2016) An empirical study on iris recognition in a mobile phone. Expert systems with Applications, 54: 328-339.

[3] Lunter J. (2021) Everyday biometrics: can face replace fingerprint recognition?. Biometric Technology Today, 2021(4): 7-10.

[4] Shawkat SA, Al-Badri KSL, Turki AI. (2019) The new hand geometry system and automatic identification. Periodicals of Engineering and Natural Sciences, 7(3): 996-1008.

[5] Mewada HK, Patel AV, Chaudhari J, MahantK, Vala A. (2020) Wavelet features embedded convolutional neural network for multiscale ear recognition. Journal of Electronic Imaging, 29(4): 043029.

[6] Shaban Al-Ani M, Mohammadi M, AlyanNezhadi MM. (2020) Gait Recognition based on Measurements of Moving Human Legs Angles. International Journal of Engineering, 33(5): 975-983.

[7] Kong A, Zhang D, Lu G. (2006) A Study of identical twins' palmprints for personal authentication. In International Conference on Biometrics (pp. 668-674). Springer, Berlin, Heidelberg.

[8] Jia W, Xia W, Zhao Y, Min H, Chen YX. (2021) 2D and 3D Palmprint and Palm Vein Recognition Based on Neural Architecture Search. International Journal of Automation and Computing, 18(3): 377-409.

[9] Aberni Y, Boubchir L, Daachi B. (2019) Multispectral palmprint recognition: a survey and comparative study. Journal of Circuits, Systems and Computers, 28(07): 1950107.

[10] Bounneche MD, Boubchir L, Bouridane A, Nekhoul B,Ali-Chérif A. (2016) Multi-spectral palmprint recognition based on oriented multiscale log-Gabor filters. Neurocomputing, 205: 274-286.

[11] Li G, Kim J. (2017) Palmprint recognition with local micro-structure tetra pattern. Pattern Recognition, 61: 29-46.

[12] Raghavendra R, Busch C. (2014) Novel image fusion scheme based on dependency measure for robust multispectral palmprint recognition. Pattern recognition, 47(6):2205-2221.

[13] Shaban Al-Ani M, Mohammadi M, AlyanNezhadi MM. (2020) Gait Recognition based on Measurements of Moving Human Legs Angles. International Journal of Engineering, 33(5): 975-983.

[14] Zhao S, Zhang B. (2020) Learning salient and discriminative descriptor for palmprint feature extraction and identification. IEEE transactions on neural networks and learning systems, 31(12): 5219-5230.

[15] Kokila MK. (2020) Accurate Palm Print Verification with Adaptive Histogram Equalization and Deep Learning Algorithm. Journal of Critical Reviews, 7(19): 3701-3710.

[16] Almaghtuf J, Khelifi F, Bouridane A. (2020) Fast and efficient difference of block means code for palmprint recognition. Machine Vision and Applications, 31(6): 1-10.

[17] Chaudhari J, Patil PM, Kosta YP. (2012) Feature extraction using Histogram of Radon Transform for Palmprint matching. International Journal of Advances in Engineering \& Technology, 5(1): 416.

[18] Jaafar H, Ibrahim S, Ramli DA. (2015) A robust and fast computation touchless palm print recognition system using LHEAT and the IFkNCN classifier. Computational intelligence and neuroscience, 2015.

[19] Hong D, Liu W, Wu X, Pan Z, Su J. (2016) Robust palmprint recognition based on the fast variation Vese-Osher model. Neurocomputing, 174: 999-1012.

[20] Rida I, Al-Maadeed S, Mahmood A, BouridaneA, Bakshi S. (2018) Palmprint identification using an ensemble of sparse representations. IEEE Access, 6: 3241-3248. 
[21] Zhang D, Kong WK, You J, Wong M. (2003) Online palmprint identification. IEEE Transactions on pattern analysis and machine intelligence, 25(9): 1041-1050.

[22] Černá D, Finěk V. (2017) Quadratic spline wavelets with short support satisfying homogeneous boundary conditions. arXiv preprint arXiv:1712.03643.

[23] The Hong Kong Polytechnic University (PolyU) Multispectral Palmprint Database [Online](2013).

http://www.comp.polyu.edu.hk/ biometrics/MultispectralPalmprint/MSP.htm, 2013.

[24] Kozik R, Choras M. (2010) Combined shape and texture information for palmprint biometrics. ratio, $1(\mathrm{~d} 2), \mathrm{d} 2$.

[25] Giełczyk A, Choraś M, Kozik R. (2019) Lightweight verification schema for image-based palmprint biometric systems. Mobile Information Systems, 2019.

[26] Zhang L, Zhang D. (2004) Characterization of palmprints by wavelet signatures via directional context modeling. IEEE Transactions on Systems, Man, and Cybernetics, Part B (Cybernetics), 34(3): 1335-1347.

[27] Agarwal S, Sharma V, Verma PK. (2019) Palm Print Recognition Using CEDA. In 2019 3rd International Conference on Computing Methodologies and Communication (ICCMC) (pp. 929-932). IEEE.

[28] Tamrakar D, Khanna P. (2016) Kernel discriminant analysis of block-wise Gaussian derivative phase pattern histogram for palmprint recognition. Journal of Visual Communication and Image Representation, 40: 432-448. 